\title{
Pseudocirrhosis after chemotherapy for gastric cancer with diffuse liver metastases: A case report
}

\author{
TOMOHITO SHINODA, TOSHIYUKI TANAHASHI, TAKUJI SAKURATANI, \\ MASATO OTA, SEITO FUJIBAYASHI, SHUNYA KIRIYAMA, KEITA MATSUMOTO, \\ KAZUNORI YAWATA, YOSHIYUKI SASAKI, SHINJI OSADA and MAKOTO YAMADA \\ Department of Surgery, Gifu Municipal Hospital, Gifu 500-8513, Japan
}

Received March 25, 2021; Accepted September 7, 2021

DOI: $10.3892 / \mathrm{mco} .2021 .2441$

\begin{abstract}
Pseudocirrhosis is a rare but important complication of metastatic cancer. We herein present the case of a patient with pseudocirrhosis occurring after a complete response to chemotherapy for metastatic gastric cancer was achieved. A 72-year-old man was diagnosed with gastric adenocarcinoma with multiple liver metastases. The patient's general condition was good, with an Eastern Cooperative Oncology Group performance status of 1 . Chemotherapy with oxaliplatin and S-1 was initiated and, after four cycles, the patient noticed sudden abdominal distension. Despite the marked regression of the liver metastases, massive ascites, segmental atrophy and esophageal varices developed, findings consistent with pseudocirrhosis. The patient achieved complete response for the primary and metastatic lesions. Following endoscopic ligation of the varices, he underwent subsequent chemotherapy with S-1 only and management of his ascites for 6 months. At 12 months after initial chemotherapy, the patient appeared to be disease-free. In conclusion, clinicians should be aware of the possibility of pseudocirrhosis in cases of cancer metastasis to the liver, including metastatic gastric cancer.
\end{abstract}

\section{Introduction}

Although rare, pseudocirrhosis is an important complication of metastatic cancer. The radiological term pseudocirrhosis has been used to describe the development of diffuse hepatic nodules in patients with cancer metastasis to the liver (1). Pseudocirrhosis presents with morphological changes similar to those of true liver cirrhosis, including lobular hepatic contour, a retracted capsular surface, segmental atrophy and an enlarged caudate lobe (2). Similar to cirrhosis, portal

Correspondence to: Dr Toshiyuki Tanahashi, Department of Surgery, Gifu Municipal Hospital, 7-1 Kashimacho, Gifu 500-8513, Japan

E-mail: 2001049@yahoo.co.jp

Key words: chemotherapy, gastric cancer, liver metastases, pseudocirrhosis hypertension that results in ascites and esophageal varices are often encountered in patients with pseudocirrhosis (3-8). Pseudocirrhosis occurs most frequently in patients with breast cancer metastasizing to the liver (5-7,9-11), but it is uncommon with other malignancies, although it has been occasionally reported in association with thyroid (3), pancreatic (12), esophageal (13), small-cell lung (14), colon (15) and gastric cancer (16). We herein report the rare case of a patient with metastatic gastric cancer who developed pseudocirrhosis after achieving complete response to chemotherapy.

\section{Case report}

A 72-year-old man was referred to the Gifu Municipal Hospital (Kashimacho, Japan) in March 2019 with anorexia, feeling of abdominal distension and general malaise. The patient was subjected to upper gastrointestinal endoscopy and was diagnosed with advanced gastric cancer type 2, a classification used in Japan to grossly describe gastric cancer in which ulcer localization is visible to the naked eye, in the greater curvature of the stomach by (Fig. 1A). Histological examination of the biopsy samples revealed well-differentiated adenocarcinoma. Blood chemistry testing revealed the following (Table I): Albumin $3.5 \mathrm{mg} / \mathrm{dl}$ (normal range, 4.1-5.1 mg/dl), aspartate aminotransferase 263 IU/1 (normal range; 13-30 IU/l), alanine aminotransferase 115 IU/1 (normal range, 10-42 IU/1), lactate dehydrogenase $1769 \mathrm{U} / 1$ (normal range, 124-222 U/l) and total bilirubin $1.8 \mathrm{mg} / \mathrm{dl}$ (normal range, $0.4-1.5 \mathrm{mg} / \mathrm{dl}$ ). The carcinoembryonic antigen level was normal $(3.7 \mathrm{ng} / \mathrm{ml}$; normal range, 0-5 ng/ml), but that of carbohydrate antigen 19-9 (CA19-9) was highly elevated at $42.5 \mathrm{U} / \mathrm{ml}$ (normal range, 0-37 U/ml). Abdominal CT examination revealed the presence of multiple liver metastases (Fig. 1B). The patient's oral intake was good, and his Eastern Cooperative Oncology Group performance status was 1 . Therefore, he received chemotherapy with S-1 (orally at $40 \mathrm{mg} / \mathrm{m}^{2}$ twice a day for 2 weeks combined with $130 \mathrm{mg} / \mathrm{m}^{2}$ oxaliplatin administered on day 1 every 3 weeks).

After 4 cycles of chemotherapy, the patient suddenly developed abdominal distention. CT examination revealed a nodular liver contour and liver volume loss, accompanied by marked regression of the liver metastases. Massive ascites and pleural effusion were also present (Fig. 2A). Radiologically, these findings mimicked those of liver cirrhosis, but the 
Table I. Changes in the blood tests following chemotherapy.

\begin{tabular}{lcccr}
\hline Blood test & $\begin{array}{c}\text { Prior to } \\
\text { treatment }\end{array}$ & $\begin{array}{c}\text { After 1 } \\
\text { treatment cycle }\end{array}$ & $\begin{array}{c}\text { After 4 treatment } \\
\text { cycles }\end{array}$ & $\begin{array}{r}12 \text { months after } \\
\text { initial treatment }\end{array}$ \\
\hline Aspartate aminotransferase (IU/l) & 263 & 57 & 54 & 37 \\
Alanine aminotransferase (IU/l) & 115 & 30 & 39 & 20 \\
Lactate dehydrogenase (IU/l) & 1,769 & - & 295 & 195 \\
Total bilirubin (mg/dl) & 1.8 & 0.9 & 2.0 & 1.3 \\
Carcinoembryonic antigen $(\mathrm{ng} / \mathrm{ml})$ & 3.7 & 4.4 & 7.2 & 5.6 \\
Carbohydrate antigen 19-9 $(\mathrm{U} / \mathrm{ml})$ & 42.4 & 12.4 & 11.0 & 11.1 \\
\hline
\end{tabular}

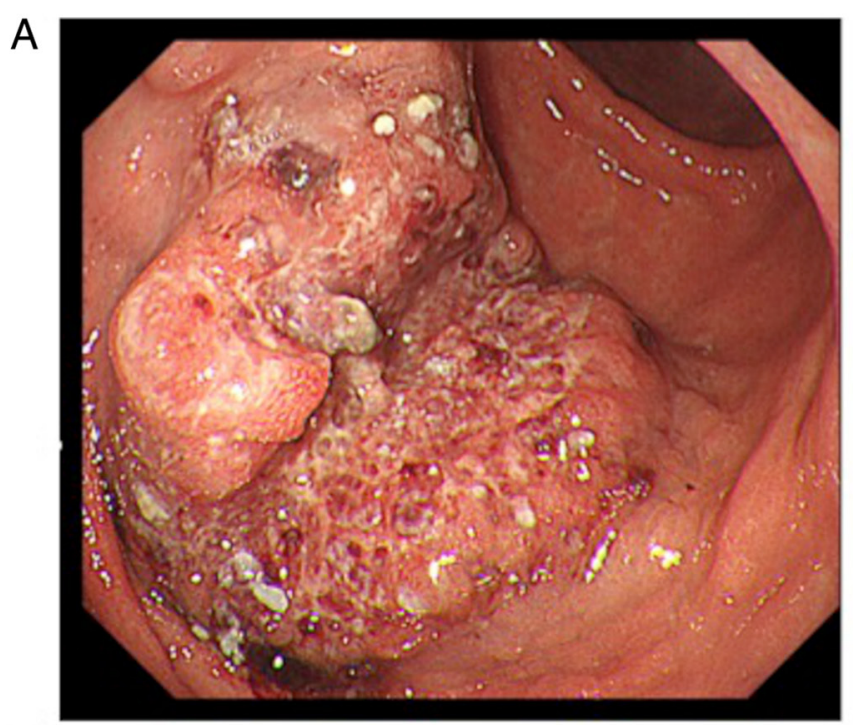

B

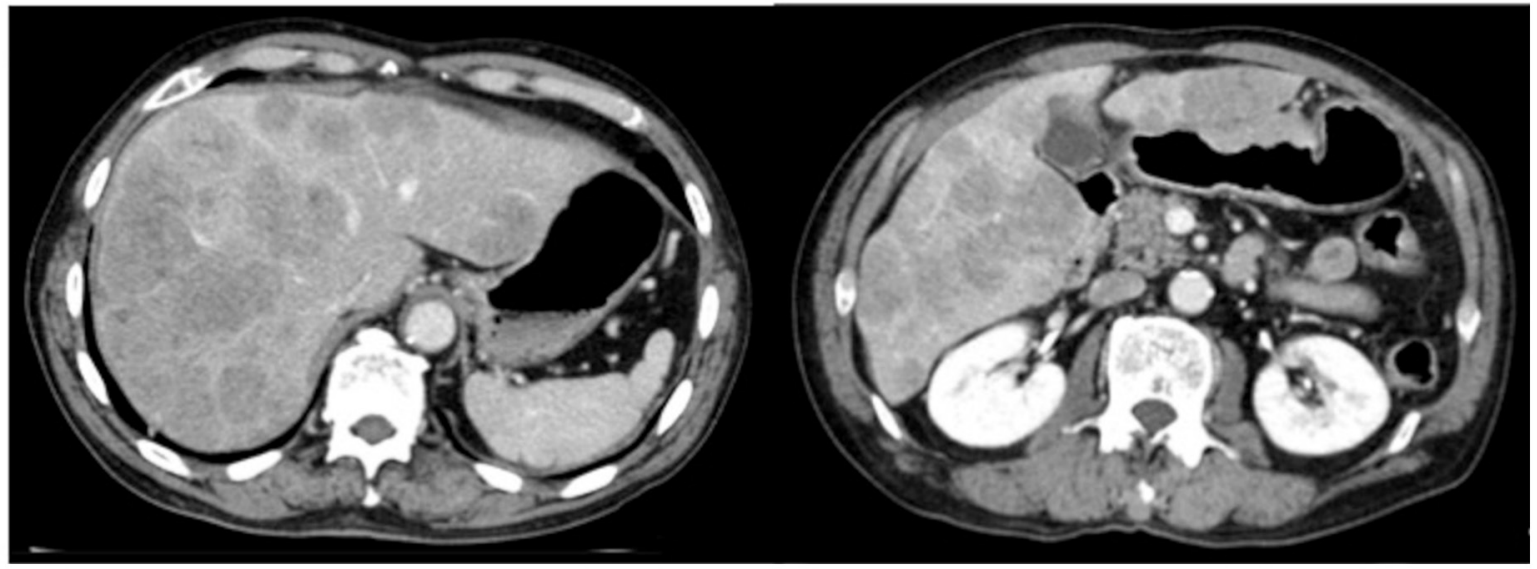

Figure 1. Imaging prior to chemotherapy. (A) Endoscopic examination revealed advanced gastric cancer, type 2, located in the lesser curvature. (B) Initial abdominal CT examination revealed multiple metastatic lesions throughout the liver.

liver enzyme levels were normal, and the CA19-9 level had decreased to $11.0 \mathrm{U} / \mathrm{ml}$ (Table I). The patient did not report excessive alcohol intake, and the serological examinations performed to investigate viral and autoimmune etiologies of cirrhosis were negative. Cytology of the transudative ascites revealed no malignant cells. Repeat upper gastrointestinal endoscopy revealed esophageal varices (red color sign) and a red scar at the site of the primary tumor (Fig. 2B); furthermore, the sample obtained by biopsy of the lesion was free of tumor cells. Positron emission tomography-CT revealed no abnormal fluorodeoxyglucose accumulation in the stomach or liver (Fig. 2C). Thus, the patient was diagnosed with pseudocirrhosis. Treatment with abdominal paracentesis and diuretics (furosemide and spironolactone) was initiated for his worsening abdominal distension and peripheral edema. The patient also underwent two sessions of endoscopic ligation of his esophageal varices with curative intent. The patient was discharged after his ascites was reduced to a manageable level, and chemotherapy was reinitiated with S-1 alone at $40 \mathrm{mg} / \mathrm{m}^{2}$ orally twice daily for 4 weeks. 

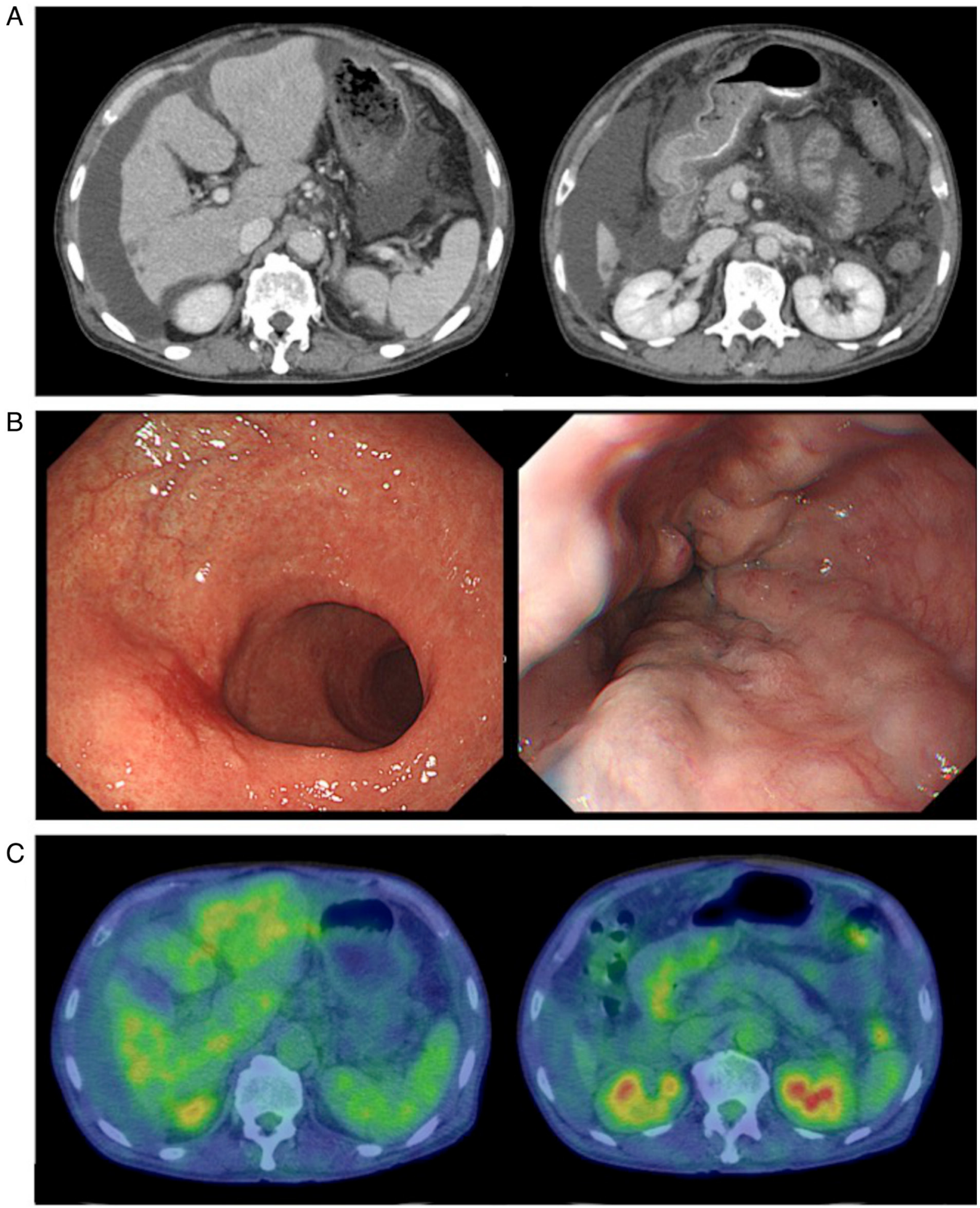

Figure 2. Imaging after four treatment cycles. (A) CT examination revealed marked regression of the liver metastases with accompanying nodular liver contour, loss of liver volume, massive ascites and pleural effusion, findings suggestive of pseudocirrhosis. (B) Endoscopic examination revealed esophageal varices, with a red scar at the site of the primary tumor. (C) Positron emission tomography-CT examination revealed no abnormal accumulation of fluorodeoxyglucose in the stomach or liver.

CT examination at 6 months after the initial treatment revealed total remission of the liver metastases and disappearance of the ascites (Fig. 3A). Therefore, the response to treatment was deemed as complete. At 12 months after the initial treatment, CT examination revealed no evidence of recurrence or metastasis. Another upper gastrointestinal endoscopic examination revealed the presence of a scar at the primary tumor site (Fig. 3B), and no tumor cells were detected following biopsy of the lesion. The patient was maintained on S-1 monotherapy, and the complete response was confirmed in April 2020 (12 months after the initial chemotherapy). 


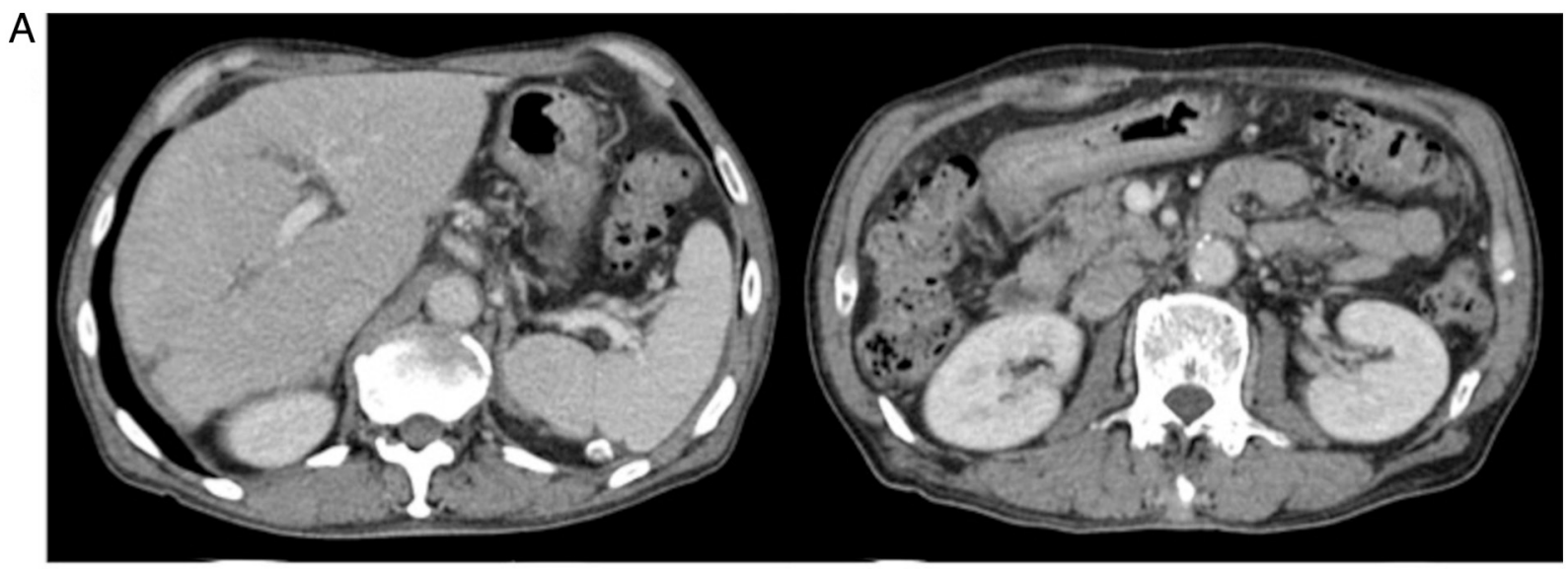

$\mathrm{B}$

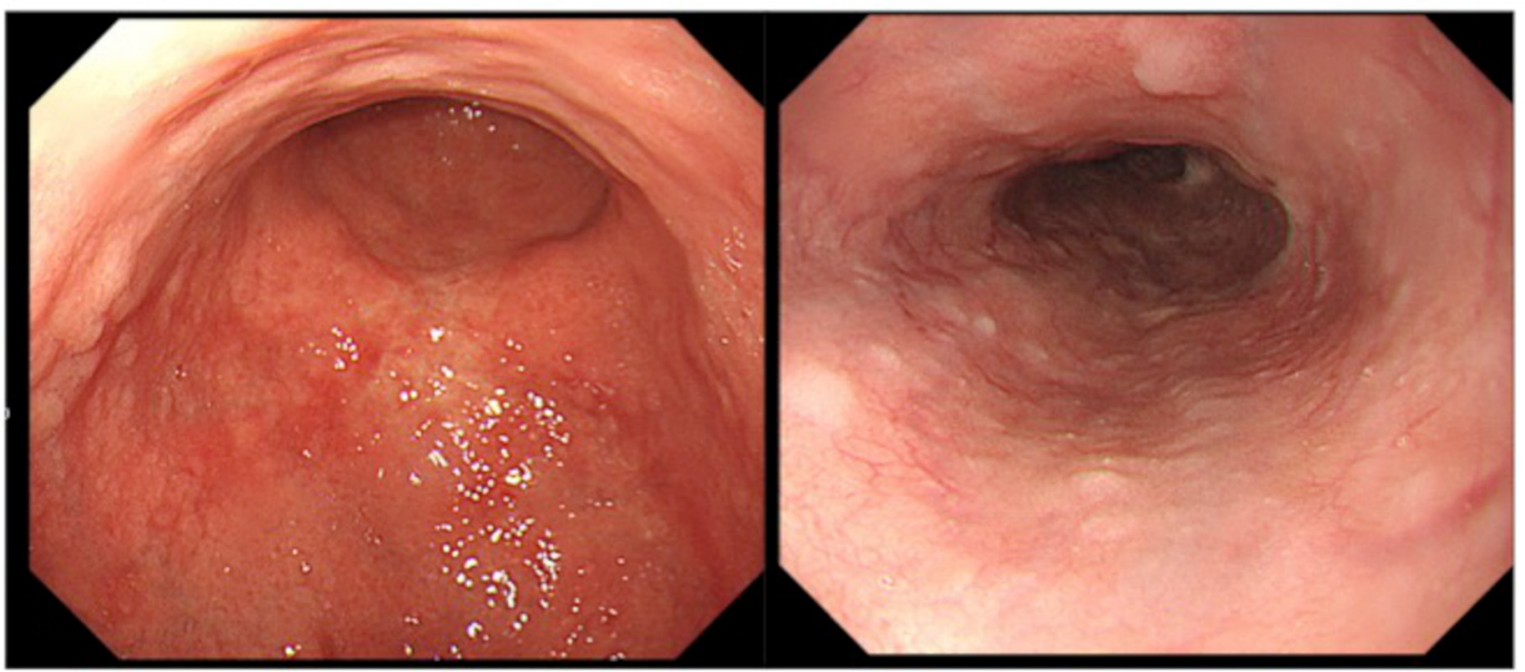

Figure 3. Imaging examination at 6 and 12 months post-treatment. (A) CT examination performed 6 months after the initial treatment revealed disappearance of the liver metastases and ascites. (B) CT examination performed 12 months after the initial treatment revealed no evidence of recurrence or metastasis.

\section{Discussion}

Pseudocirrhosis is a term used to describe a complication of cancer with multiple liver metastases, and its radiological appearance is similar to that of cirrhosis (17). However, there is no examination that can definitively distinguish pseudocirrhosis from cirrhosis, and the typical histopathological findings of cirrhosis are lacking. The precise mechanism underlying the development of pseudocirrhosis remains unclear. However, it is currently attributed to two etiologies, either a process related to hepatic metastases, or toxicity resulting from systemic therapy $(5,6,11)$. In the former, chemotherapy can induce hepatic retraction with a lobular contour from either an increase or decrease in the size of the subjacent tumor $(2,9)$. In the latter, pseudocirrhosis can occur with or without prior systemic chemotherapy. Hepatic histology in this case may exhibit extensive tumor infiltration and desmoplastic fibrosis $(5,6,11)$.

The only known case to date of pseudocirrhosis arising from metastatic gastric cancer was reported by Mitani et al (16). The majority of other reports on pseudocirrhosis are associated with hepatic metastasis of breast cancer $(2,4-11,18)$. Furthermore, although there have been some case reports of pseudocirrhosis in various primary cancers with liver metastases $(3,12-17,19)$, these reports suggested no correlation with the specific type of cancer.
Nodular regenerative hyperplasia, which presents as a widespread transformation of normal hepatic parenchyma into regenerative nodules with little or no bridging fibrosis, may also be associated with the development of pseudocirrhosis (2). There are some reports that pseudocirrhosis occurs when using oxaliplatin for gastric, colon, or pancreatic cancer $(12,15,16)$, and oxaliplatin is well known to cause nodular regenerative hyperplasia. However, the chemotherapeutic agents that can worsen pseudocirrhosis remain unclear, and no chemotherapeutic agent has yet been identified as the sole culprit $(4,19)$.

Adike et al (18) reported abdominal distention with ascites as the most common initial presentation of pseudocirrhosis. In addition, certain severe complications, such as hepatic encephalopathy and variceal bleeding, may occasionally result in a fatal outcome (3-8), which indicates the clinical significance of pseudocirrhosis, as well as classic cirrhosis, and the importance of early detection and appropriate management (16).

In conclusion, pseudocirrhosis may occur during the achievement of a chemotherapeutic response in metastatic gastric or breast cancer. Thus, clinicians must be aware of this entity and recognize the onset of pseudocirrhosis in order to administer appropriate treatment in a timely manner, even when the patients are receiving chemotherapy for gastric cancer. 


\section{Acknowledgements}

Not applicable.

\section{Funding}

No funding was received.

\section{Availability of data and materials}

The datasets used and/or analyzed during the current study are available from the corresponding author on reasonable request.

\section{Authors' contributions}

TSh and TT analyzed and interpreted the data, wrote the manuscript and confirm the authenticity of the raw data. TSh, TT, TSa, MO, SF, SK, KM, KY, YS, SO and MY evaluated the patient and participated in his therapy. All the authors have read and approved the final manuscript.

\section{Ethics approval and consent to participate}

Not applicable.

\section{Patient consent for publication}

The patient provided written informed consent for the publication of the case details and any associated images.

\section{Competing interests}

The authors declare that they have no competing interests.

\section{References}

1. Sharma A, Houshyar R, Bhosale P, Choi JI, Gulati R and Lall C: Chemotherapy induced liver abnormalities: An imaging perspective. Clin Mol Hepatol 20: 317-326, 2014.

2. Young ST, Paulson EK, Washington K, Gulliver DJ, Vredenburgh JJ and Baker ME: CT of the liver in patients with metastatic breast carcinoma treated by chemotherapy: Findings simulating cirrhosis. AJR Am J Roentgenol 163: 1385-1388, 1994.

3. Harry BL, Smith ML, Burton JR Jr, Dasari A, Eckhardt SG and Diamond JR: Medullary thyroid cancer and pseudocirrhosis: Case report and literature review. Curr Oncol 19: e36-e41, 2012.
4. Qayyum A, Lee GK, Yeh BM, Allen JN, Venook AP and Coakley FV: Frequency of hepatic contour abnormalities and signs of portal hypertension at $\mathrm{CT}$ in patients receiving chemotherapy for breast cancer metastatic to the liver. Clin Imaging 31: 6-10, 2007.

5. Sass DA, Clark K, Grzybicki D, Rabinovitz $M$ and Shaw-Stiffel TA: Diffuse desmoplastic metastatic breast cancer simulating cirrhosis with severe portal hypertension: A case of 'pseudocirrhosis'. Dig Dis Sci 52: 749-752, 2007.

6. Nascimento AB, Mitchell DG, Rubin R and Weaver E: Diffuse desmoplastic breast carcinoma metastases to the liver simulating cirrhosis at MR imaging: Report of two cases. Radiology 221: 117-121, 2001.

7. Chandrakar V and Isaacs C: Breast cancer-related pseudocirrhosis and esophageal varices. Breast J 11: 301-302, 2005.

8. Jeong WK, Choi SY and Kim J: Pseudocirrhosis as a complication after chemotherapy for hepatic metastasis from breast cancer. Clin Mol Hepatol 19: 190-194, 2013.

9. Fennessy FM, Mortele KJ, Kluckert T, Gogate A, Ondategui-Parra S, Ros P and Silverman SG: Hepatic capsular retraction in metastatic carcinoma of the breast occurring with increase or decrease in size of subjacent metastasis. AJR Am J Roentgenol 182: 651-655, 2004.

10. Schreiner SA, Gorman B and Stephens DH: Chemotherapy-related hepatotoxicity causing imaging findings resembling cirrhosis. Mayo Clin Proc 73: 780-783, 1998.

11. Lee SL, Chang ED, Na SJ, Kim JS, An HJ, Ko YH and Won HS: Pseudocirrhosis of breast cancer metastases to the liver treated by chemotherapy. Cancer Res Treat 46: 98-103, 2014.

12. Kang SP, Taddei T, McLennan B and Lacy J: Pseudocirrhosis in a pancreatic cancer patient with liver metastases: A case report of complete resolution of pseudocirrhosis with an early recognition and management. World J Gastroenterol 14: 1622-1624, 2008.

13. Kobashigawa C, Nakamoto M, Hokama A, Hirata T, Kinjo F and Fujita J: Pseudocirrhosis in metastatic esophageal cancer. South Med J 103: 488-489, 2010.

14. Ojeda VJ: Metastatic oat cell carcinoma simulating liver cirrhosis. N Z Med J 86: 480-481, 1977.

15. Battisti S, Guida FM, Pagliara E, Tonini G, Zobel BB and Santini D: Pseudocirrhosis after anti-EGFR-based neoadjuvant therapy for hepatic metastasis from colon cancer: A different point of view. Clin Colorectal Cancer 13: e13-e15, 2014.

16. Mitani S, Kadowaki S, Taniguchi H, Muto H and Muro K: Pseudocirrhosis in gastric cancer with diffuse liver metastases after a dramatic response to chemotherapy. Case Rep Oncol 9: 106-111, 2016.

17. Kumamoto K, Endo S, Isohata N, Nirei A, Nemoto D, Utano K, Saito T and Togashi K: Pseudocirrhosis caused by regorafenib in an advanced rectal cancer patient with multiple liver metastases. Mol Clin Oncol 6: 63-66, 2017.

18. Adike A, Karlin N, Menias C and Carey EJ: Pseudocirrhosis: A case series and literature review. Case Rep Gastroenterol 10: 381-391, 2016.

19. Ngo D, Jia JB, Green CS, Gulati AT and Lall C: Cancer therapy related complications in the liver, pancreas, and biliary system: An imaging perspective. Insights Imaging 6: 665-677, 2015.

c) (†) $\Theta$ This work is licensed under a Creative Commons

EY NC ND Attribution-NonCommercial-NoDerivatives 4.0 International (CC BY-NC-ND 4.0) License. 